\title{
High-level secretion of native recombinant human calreticulin in yeast
}

\author{
Evaldas Čiplys ${ }^{1}$, Eimantas Žitkus ${ }^{1}$, Leslie I. Gold², Julien Daubriac², Savvas C. Pavlides², Peter Højrup³, \\ Gunnar Houen ${ }^{4}$, Wen-An Wang ${ }^{5}$, Marek Michalak ${ }^{5}$ and Rimantas Slibinskas ${ }^{1 *}$
}

\begin{abstract}
Background: Calreticulin (CRT) resides in the endoplasmic reticulum (ER) and functions to chaperone proteins, ensuring proper folding, and intracellular $\mathrm{Ca}^{2+}$ homeostasis. Emerging evidence shows that CRT is a multifunctional protein with significant roles in physiological and pathological processes with presence both inside and outside of the $E R$, including the cell surface and extracellular space. These recent findings suggest the possible use of this ER chaperone in development of new therapeutic pharmaceuticals. Our study was focused on human CRT production in two yeast species, Saccharomyces cerevisiae and Pichia pastoris.
\end{abstract}

Results: Expression of a full-length human CRT precursor including its native signal sequence resulted in high-level secretion of mature recombinant protein into the culture medium by both S. cerevisiae and P. pastoris. To ensure the structural and functional quality of the yeast-derived CRTs, we compared yeast-secreted human recombinant CRT with native CRT isolated from human placenta. In ESI-MS (electrospray ionization mass spectrometry), both native and recombinant full-length CRT showed an identical molecular weight (mass) of 46,466 Da and were monomeric by non-denaturing PAGE. Moreover, limited trypsin digestion yielded identical fragment patterns of calcium-binding recombinant and native CRT suggesting that the yeast-derived CRT was correctly folded. Furthermore, both native and recombinant CRT induced cellular proliferation (MTS assay) and migration of human dermal fibroblasts (in vitro wound healing assay) with the same specific activities (peak responses at 1-10 $\mathrm{ng} / \mathrm{ml}$ ) indicating that the functional integrity of yeast-derived CRT was completely preserved. Simple one-step purification of CRT from shake-flask cultures resulted in highly pure recombinant CRT protein with yields reaching $75 \%$ of total secreted protein and with production levels of 60 and $200 \mathrm{mg} / \mathrm{l}$ from S. cerevisiae and P. pastoris, respectively. Finally, cultivation of P. pastoris in a bioreactor yielded CRT secretion titer to exceed $1.5 \mathrm{~g} / \mathrm{l}$ of culture medium.

Conclusions: Yeasts are able to correctly process and secrete large amounts of mature recombinant human CRT equally and fully biologically active as native human CRT. This allows efficient production of high-quality CRT protein in grams per liter scale.

\section{Background}

CRT functions in the ER as a calcium-binding chaperone involved in a variety of biological processes including quality control of protein folding [1-3], regulation of calcium homeostasis $[2,4,5]$ and MHC class I antigen processing $[6,7]$. In addition to these essential intracellular functions, CRT has other important functional

\footnotetext{
*Correspondence: rimantas.slibinskas@bti.vu.lt

${ }^{1}$ Department of Eukaryote Gene Engineering, Institute of Biotechnology,

Vilnius University, V.A. Graičiūno 8, 02241 Vilnius, Lithuania

Full list of author information is available at the end of the article
}

roles outside of the ER that are critical to various physiological and disease processes, particularly stress-related disease [8]. For example, CRT has a significant role in both the innate and adaptive immune response and cell surface CRT is required for phagocytosis of apoptotic cells [9]. In this vein, both intracellular and extracellular CRT are important in the host immune response to cancer with respect to activation of $\mathrm{T}$ cells, peptide loading with tumor antigens, and in the phagocytosis of tumor cells expressing cell surface CRT, by dendritic cells. CRT is also important to the success of certain chemotherapies [10-12]. In addition, CRT is integrally important in 
the process of healing cutaneous wounds $[13,14]$. These functions are directed by the surface-exposed or secreted protein form of CRT $[14,15]$. The translocation of CRT to the cell surface can be induced by ER stress in some cell types, which is triggered by various stimuli including anthracyclines, irradiation and reduction of ER $\mathrm{Ca}^{2+}$ levels [16-18]. Importantly, since exogenous CRT rescues CRT-deficient cells in numerous and different CRT-dependent functions, such as adhesion, migration, phagocytosis, and immunoregulation [8], exogenously supplied CRT has significant therapeutic potential for a variety of indications including impaired diabetic wound healing and cancer therapy $[8,10,11,13,14,19]$. In fact, chronic wound healing and particularly impaired cutaneous healing as a consequence of diabetes is a global serious unmet medical need and economic challenge (26 million worldwide patients). Taken together, future fundamental, applied and therapeutic studies and use will likely require large amounts of affordable high-quality recombinant human CRT protein with native functional capacity, insofar as possible.

Here we show that expression of a full-length human CRT precursor in yeast cells can be employed to obtain a high level of secretion of mature native recombinant CRT protein. Fed-batch fermentation of $P$. pastoris culture resulted in more than $1.5 \mathrm{~g} / \mathrm{l}$ CRT secretion yield. Comparison of yeast-secreted recombinant CRT to native CRT isolated from human placenta showed that the recombinant protein has apparent similar molecular and functional properties as the native protein. From this study, we can conclude that yeast is an excellent host for industrially relevant production of native recombinant CRT protein.

\section{Results and discussion}

\section{Expression and purification of human CRT from yeasts}

S. cerevisiae and P. pastoris from culture medium

Our results herein show that expression of a full-length human CRT precursor including its native signal sequence resulted in a high-level secretion of the recombinant protein into the culture medium by two yeast species, S. cerevisiae and P. pastoris. It should be noted that the expressed human CRT polypeptide precursor contained exactly the same native amino acid sequence as CRT precursor in human cells. Neither yeast secretion signal sequences, nor any tags for purification were used in this study. In the $S$. cerevisiae system, we expressed the gene encoding CRT under control of the yeast PGK1 gene promoter in the same vector, pFDC [20], that was previously used for the expression of secreted human BiP and ERp57 in yeast [21, 22] and show that CRT was similarly secreted into the culture medium (Fig. 1). However, quantities of the secreted CRT protein were

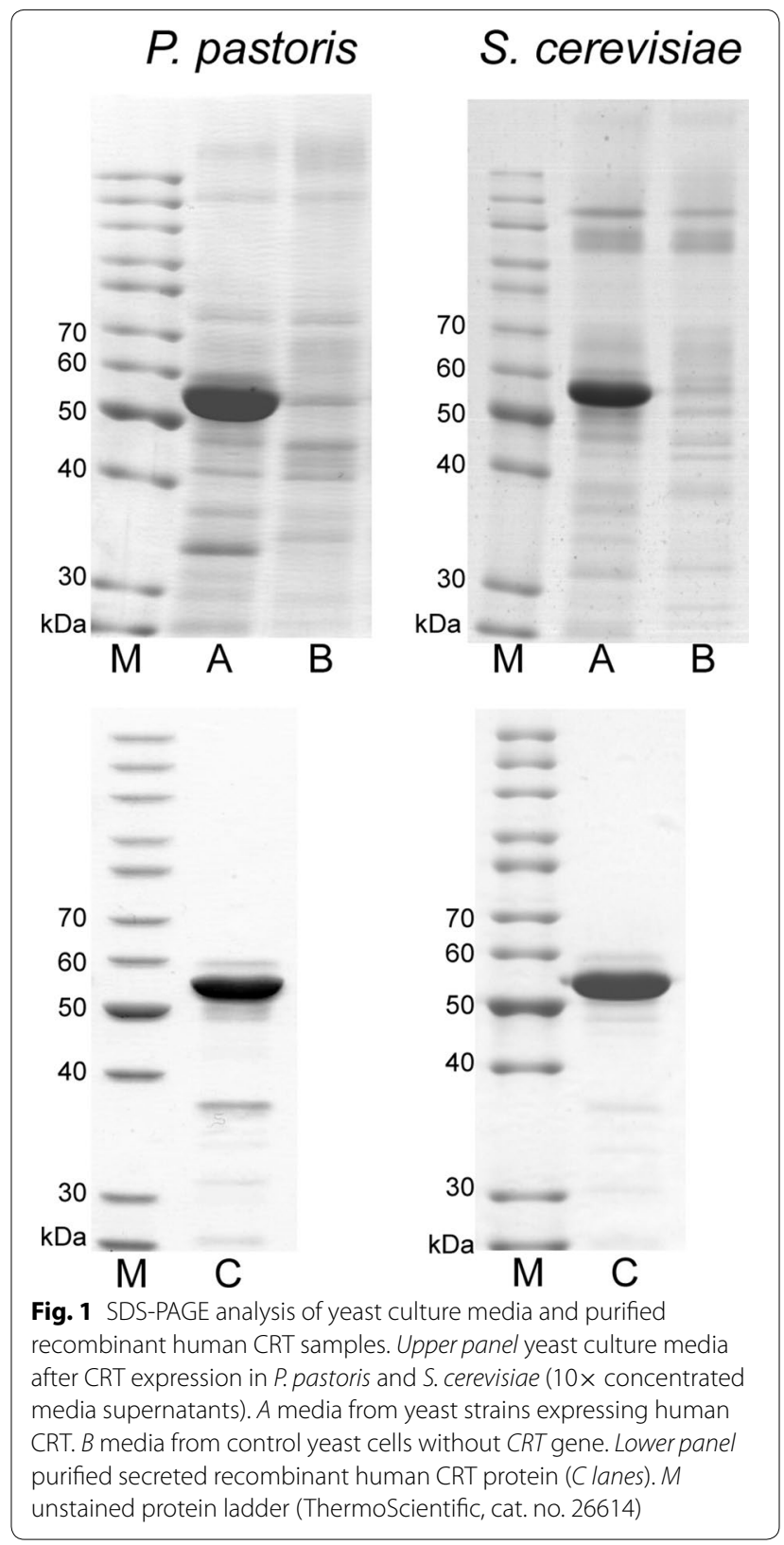

much higher than previously observed for human BiP or ERp57. According to data obtained from densitometric analysis of SDS-PAGE gels, secreted human recombinant CRT constituted approximately $60-65 \%$ of the total S. cerevisiae secreted proteins. The CRT secretion titer was approximately $60-65 \mathrm{mg}$ from $1 \mathrm{~L}$ of yeast culture medium. The amount of secreted CRT in S. cerevisiae culture supernatant was about four- to fivefold higher than either human BiP or ERp57 under the same conditions (for direct comparison of secretion levels see SDSPAGE gel in Additional file 1). CRT secretion was also achieved by using methanol-inducible yeast $A O X 1$ gene 
promoter in P. pastoris (Fig. 1). Shake flask cultures of the selected P. pastoris transformant, CPp9, with multicopy integrations of CRT expression cassettes yielded approximately $180-200 \mathrm{mg} / \mathrm{l}$ of secreted CRT and the purity of the full-length mature human CRT recombinant protein in crude $P$. pastoris culture medium was approximately 70-75 \%. There were also a few minor bands of partially degraded CRT protein detected in the culture media from both yeasts by SDS-PAGE and Western blot, but these bands were not included in calculations.

The high-level secretion of recombinant human CRT in yeast culture media allowed one-step purification by Q-Sepharose ion-exchange chromatography. CRT is an acidic protein with a pI of 4.29 and contains an Asp/ Glu/Lys-rich C-domain. Such biophysical characteristics allow strong binding to an anion-exchange column even at low $\mathrm{pH}$ and increased ionic strength. This purification step efficiently removed yeast proteins and other impurities. However, lower molecular weight (MW) forms of CRT were co-purified with the main form of the full-length CRT protein in the same single elution peak (Additional file 2). There was also a slightly higher MW protein form detected by SDS-PAGE in elution fractions of purified CRT from both yeasts, which was more prominent in $P$. pastoris-derived preparation (Additional file $2 b, d$ ). The elution profile showed that the CRT peak was not symmetrical and even had a smaller shoulder in preparation from P. pastoris (Additional file 2c), possibly due to presence of additional minor protein forms observed. Western blotting analysis showed that minor bands visible by SDS-PAGE of purified protein also represent CRT as they reacted with monoclonal anti-CRT antibody (Additional file 3). It was also evident that CRT fragments of lower MW were generated during biosynthesis, because they were also observed in yeast culture medium (Fig. 1; Additional file 3). Moreover, we did not observe such multiple fragments of lower MW by native PAGE (Fig. 2). It seems that after proteolytic cleavage lower MW fragments are still maintained within CRT molecules by intra-molecular interactions, while they are separated only under denaturing conditions. Probably, such protein form should be considered as "nicked", rather than "partially degraded". SDS-PAGE and immunoblotting showed the same overall pattern of "nicked" or partially degraded forms between different preparations (Additional file 4). According to densitometric analysis of Coomassie-stained SDS-PAGE gels, the major intact CRT protein form constituted for approximately $80 \%$ in P. pastoris- and $85 \%$ in S. cerevisiae-derived preparations. The overall purity of CRT including minor protein forms was considerably higher than $90 \%$ in preparations from both yeasts. Furthermore, recombinant CRT purified from P. pastoris, analysed for protein impurities by

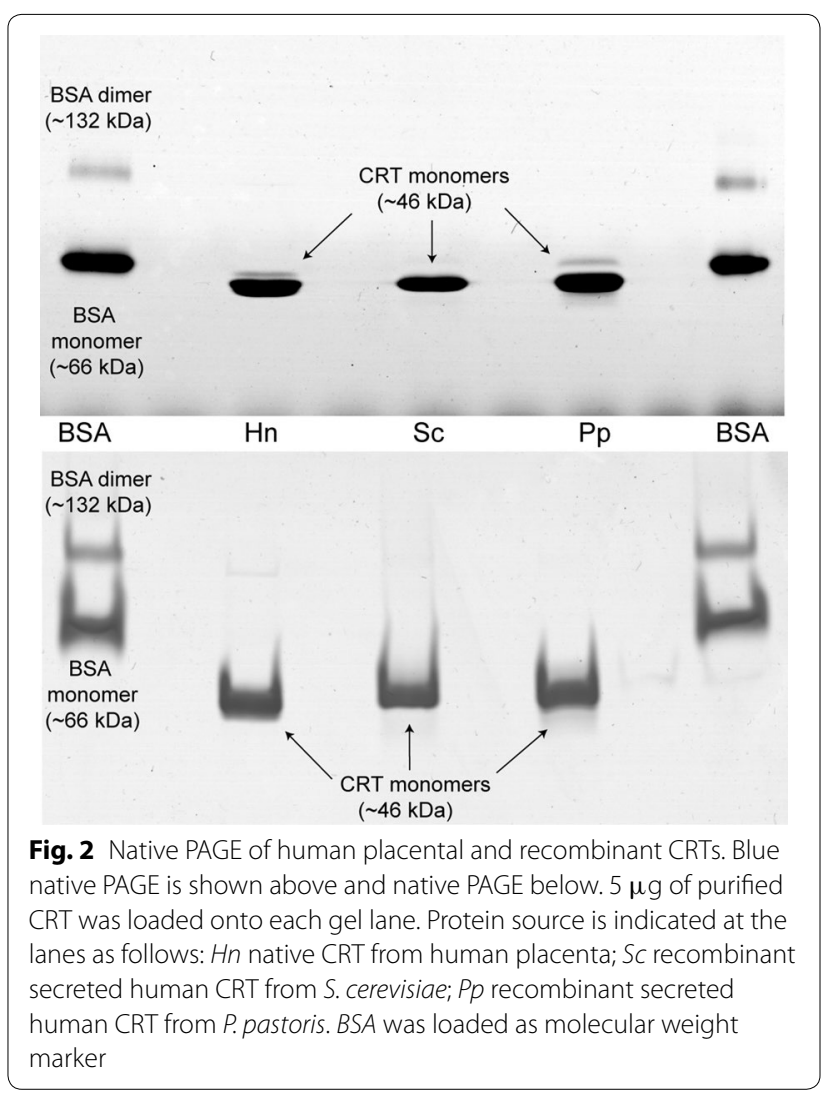

quantitative evaluation of tryptic peptides using a HDMS Synapt G2 mass spectrometer, showed 98-99 \% purity. Therefore, this simple one-step purification generated highly pure recombinant secreted human CRT containing minor amounts of nicked or partially degraded protein forms. The yields of purified CRT were 45-50 and $130-150 \mathrm{mg} / \mathrm{l}$ in S. cerevisiae and P. pastoris, respectively.

\section{Recombinant human CRT secreted by yeast and CRT protein isolated from human placenta have similar molecular features}

The pattern from tryptic peptide mass fingerprinting of purified secreted CRT from both yeast species was confirmed to be the same as mature CRT sequence from human cells (without the signal sequence) including a tryptic peptide (EPAVYFK) corresponding to the $\mathrm{N}$-terminal sequence of native mature CRT [23-25] (Fig. 3). Moreover, using a comprehensive technique with a HDMS Synapt G2 system, peptide mass fingerprinting of $P$. pastoris-secreted CRT was able to provide $>90 \%$ amino acid sequence coverage (Fig. 3). Although we were not able to identify the $\mathrm{N}$-terminal tryptic peptide by this method, a C-terminal human CRT peptide including the intact ER retention/ retrieval signal KDEL was identified (underlined in Fig. 3). 


\author{
Human CRT from S. cerevisiae: \\ 1 MLLSVPLLLG LLGLAVAEPA VYFKEQFLDG DGWTSRWIES KHKSDFGKFV LSSGKFYGDE \\ 61 EKDKGLQTSQ DARFYALSAS FEPFSNKGQT LVVQFTVKHE QNIDCGGGYV KLFPNSLDQT \\ 121 DMHGDSEYNI MFGPDICGPG TKKVHVIFNY KGKNVLINKD IRCKDDEFTH LYTLIVRPDN \\ 181 TYEVKIDNSQ VESGSLEDDW DFLPPKKIKD PDASKPEDWD ERAKIDDPTD SKPEDWDKPE \\ 241 HIPDPDAKKP EDWDEEMDGE WEPPVIQNPE YKGEWKPRQI DNPDYKGTWI HPEIDNPEYS \\ 301 PDPSIYAYDN FGVLGLDLWQ VKSGTIFDNF LITNDEAYAE EFGNETWGVT KAAEKQMKDK \\ 361 QDEEQRLKEE EEDKKRKEEE EAEDKEDDED KDEDEEDEED KEEDEEEDVP GQAKDEL
}

Human CRT from $P$. pastoris:

1 MLLSVPLLLG LLGLAVAEPA VYFKEQFLDG DGWTSRWIES KHKSDFGKFV LSSGKFYGDE

61 EKDKGLQTSQ DARFYALSAS FEPFSNKGQT LVVQFTVKHE QNIDCGGGYV KLFPNSLDQT

121 DMHGDSEYNI MFGPDICGPG TKKVHVIFNY KGKNVLINKD IRCKDDEFTH LYTLIVRPDN

181 TYEVKIDNSQ VESGSLEDDW DFLPPKKIKD PDASKPEDWD ERAKIDDPTD SKPEDWDKPE

241 HIPDPDAKKP EDWDEEMDGE WEPPVIQNPE YKGEWKPRQI DNPDYKGTWI HPEIDNPEYS

301 PDPSIYAYDN FGVLGLDLWQ VKSGTIFDNF IITNDEAYAE EFGNETWGVT KAAEKQMKDK

361 QDEEQRLKEE EEDKKRKEEE EAEDKEDDED KDEDEEDEED KEEDEEEDVP GQAKDEL

Fig. 3 Tryptic peptide mass fingerprinting of yeast-secreted CRT protein. Purified secreted CRT protein was analyzed by trypsin digestion and MALDI-TOF/TOF tandem MS/MS (upper panels) or nano-LC coupled with HDMS Synapt G2 mass spectrometer (lower panels). Human CRT was identified with $\sim 66 \%$ or $~ 91 \%$ sequence coverage in S. cerevisiae- or P. pastoris-derived samples, respectively (identified sequences are indicated in bold). The $\mathrm{N}$-terminal tryptic peptide (begins not from lysine or arginine), and C-terminal tryptic peptide (contains C-terminal -KDEL sequence), are underlined

To ensure the structural and functional integrity of the yeast-derived CRTs, we compared yeast-secreted human recombinant CRT with native CRT isolated from human placenta [26]. ESI-MS of a whole intact native and recombinant CRTs showed basically the same molecular weight (MW) of approximately $46,466 \mathrm{Da}$, which exactly corresponds to the theoretically calculated MW of mature human CRT (Fig. 4). Moreover, N-terminal sequencing by Edman degradation confirmed that the first five $\mathrm{N}$-terminal amino acid sequences of $P$. pastoris- and $S$. cerevisiae-expressed proteins were $\mathrm{NH}_{2}$ EPAVY and corresponded to the $\mathrm{N}$-terminal amino acid sequence of mature human CRT. Taken together, these results indicated that native CRT human ER signal sequence was recognized and correctly processed (i.e., cleaved from the precursor to form the mature protein) in yeast cells, and this supported translocation of recombinant protein into the ER lumen followed by secretion into the culture media. Furthermore, according to the determined MW, both native and recombinant CRTs are pure polypeptide chains without additional groups attached due to post-translational modification. The lack of such post-translational modifications as glycosylation and phosphorylation, was shown in previous analysis of human placental CRT [26]. Nevertheless, it should be noted that our study was focused on comparison of CRTs from different sources, rather than on analysis of possible post-translational modifications. The protein should contain a disulfide bond [26] and there were reports on various CRT modifications including acetylation of 


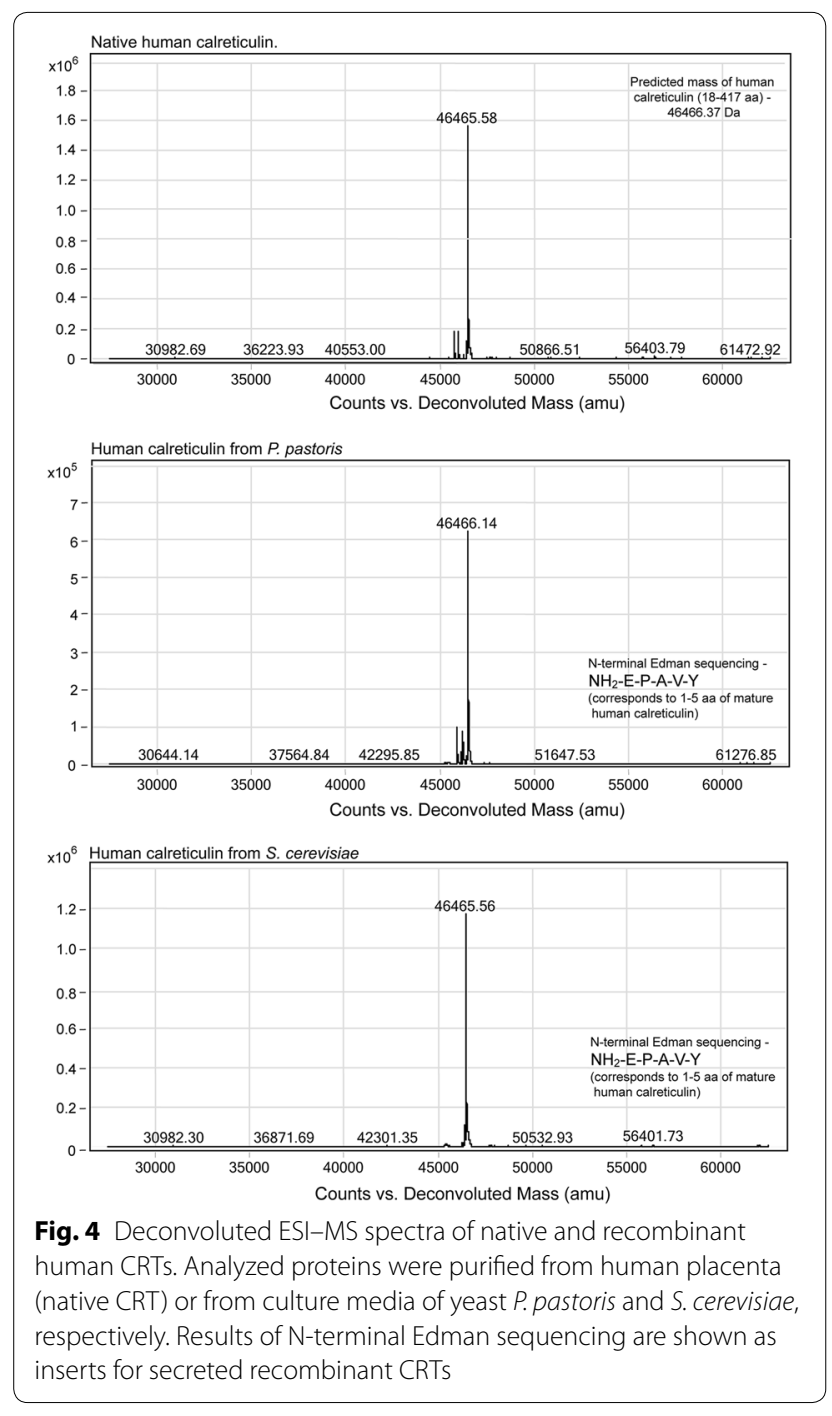

lysine residues [27, 28], glycosylation [29] and citrullination [30] in different tissues or under specific conditions. Some modification of both recombinant and native placental CRTs might be suspected from a minor form of slightly higher MW observed in SDS-PAGE, as it was mentioned above. According to densitometric scanning of SDS-PAGE gels it constituted up to $2 \%$ of protein purified from P. pastoris or human placenta, and even less amount of protein from S. cerevisiae. This minor band should represent the same CRT protein as it reacted with anti-CRT antibodies (Additional files 1, 3 for S. cerevisiae and P. pastoris, respectively). However, both minor and major bands have been characterised by MS and no differences were seen. The most likely explanation may be that the slower migrating band represents a separate conformation, which is stable during the time of electrophoresis, possibly proline cis-trans isomerism (CRT has many prolines). At least, they certainly do not represent acetylation or glycosylation. Although we did not perform extensive tests for modifications and can thus not exclude that some modifications may still exist, the methods used in this study did not detect any difference in modification status between native and recombinant CRTs. Taken together, based on the analyses herein, the native and recombinant CRT proteins appear to show similar molecular characteristics.

\section{Oligomerization and conformation of yeast-secreted and placental CRTs}

Oligomerization analysis by native and blue native PAGE showed that both placental and recombinant CRTs were present only in monomeric form (Fig. 2). However, we observed a slight difference in mobility of CRTs purified from human placenta and yeast culture media. Native human protein migrated slightly faster than recombinant CRTs, and this suggested a conformational difference. In order to check possible influence of different buffers used for storage of recombinant and placental CRTs, we have transferred the latter to storage buffer of recombinant CRTs and repeated both native PAGEs. Indeed, buffer change resulted in slower migration of placental CRT and it became very similar to that of yeast-secreted proteins (Additional file 5).

Conformation of native and recombinant CRTs was analysed by limited proteolysis with trypsin. It has been reported that the binding of $\mathrm{Ca}^{2+}$ to $\mathrm{CRT}$ protects a 20-30 kDa CRT domain against trypsin digestion due to a $\mathrm{Ca}^{2+}$-dependent conformational change in the protein [31]. In agreement with this report, by SDS-PAGE analysis, the same $\sim 23 \mathrm{kDa}$ CRT fragment and digestion pattern was obtained for the native and recombinant CRTs in the presence of $\mathrm{Ca}^{2+}$ ions (Fig. 5 middle panel), whereas addition of EGTA to chelate $\mathrm{Ca}^{2+}$ resulted in rapid protein degradation and the absence of a protected fragment (Fig. 5 right panel). We also noticed that CRT proteins showed an additional minor trypsin-resistant fragment of $\sim 50 \mathrm{kDa}$ (Fig. 5 middle panel). A similar $\sim 50 \mathrm{kDa}$ trypsin-resistant fragment for the placental CRT was reported in a previous study [26]. Taken together, native placental and recombinant human CRTs showed similar sensitivity to trypsin digestion indicating a correct folding that has also been previously reported for rabbit CRT expressed in P. pastoris [32]. The C-terminal part of the rabbit protein was removed fairly rapidly to give an apparent MW 50-kDa fragment, which was further degraded, leaving a protease-resistant fragment of an apparent $27 \mathrm{kDa}$ [31]. Therefore, limited proteolysis with trypsin indicated that yeast-expressed human CRT was a correctly folded $\mathrm{Ca}^{2+}$ binding protein that harbored similar properties to both native human placental CRT [26] and recombinant rabbit CRT expressed in P. pastoris [31, 32]. 


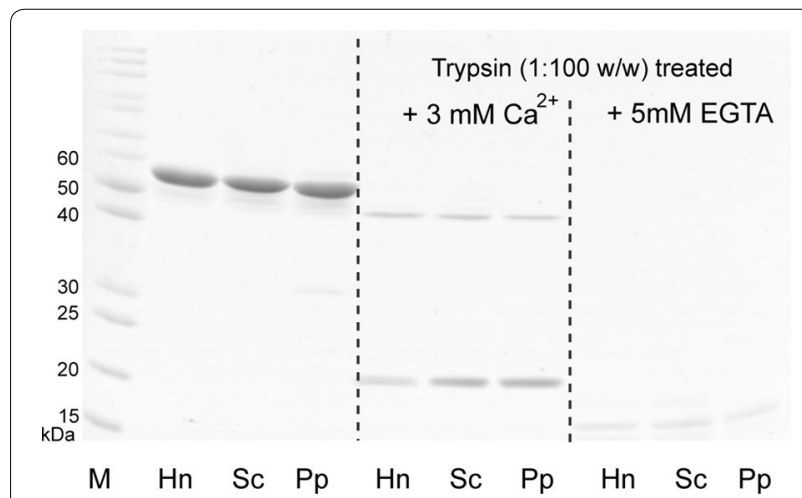

Fig. 5 Partial digestion of native and recombinant human CRTs with trypsin. M unstained protein ladder (ThermoScientific, cat. no. 26614). Undigested CRTs are loaded to the left, CRTs digested with trypsin in the presence of $3 \mathrm{mM} \mathrm{CaCl}_{2}$-in the middle, whereas CRTs digested with trypsin after addition of EGTA to chelate calcium ions - in the right gel lanes. Source of protein is indicated as described in Fig. 2 legend

\section{Functional analysis of the recombinant and native human CRTs}

It was previously shown that topically applied CRT markedly enhanced the rate and quality of wound healing in porcine and diabetic mouse models [8, 13, 14, 33]. In these studies, CRT was shown to dose-dependently induce wound healing functions of migration, proliferation, and matrix protein induction in human dermal fibroblasts as previously shown in identical in vitro assays $[13,14]$. To ensure that CRT secreted from yeast was biologically active, we directly compared effects of native and recombinant CRTs in vitro, for their ability to induce human fibroblast proliferation, using an MTS cell proliferation assay, (Fig. 6) and migration, using a classic in vitro wound healing scratch plate assay (Fig. 7). As shown in Fig. 6, human placental and yeast-derived CRT from both, $P$. pastoris and $S$. cerevisiae, stimulated proliferation at the same peak of activity of $10 \mathrm{ng} / \mathrm{ml}$. At this concentration, native CRT stimulated proliferation by 1.25 -fold $(\mathrm{p}<0.01)$ and CRT from $P$. pastoris and S. cerevisiae showed a $1.37(\mathrm{p} \leq 0.0001)$ and 1.344 -fold ( $\mathrm{p} \leq 0.001$ ) increase, respectively; (untreated control of $0.5 \%$ serum is set at $1.0 ; \mathrm{n}=6$ ). By comparison, the $10 \%$ FBS positive control stimulated proliferation 1.6fold over untreated control $(\mathrm{p} \leq 0.0001)$. There was no statistically significant difference among all of the CRTs with all treatment doses. Therefore, we conclude that all CRTs were functionally indistinguishable (Fig. 6). As we have previously shown with receptor mediated responses such as cell proliferation and migration, a peak of activity is obtained, which wanes at higher concentrations of the protein $[13,14]$. This can be explained by receptor saturation at concentrations higher than the peak activity

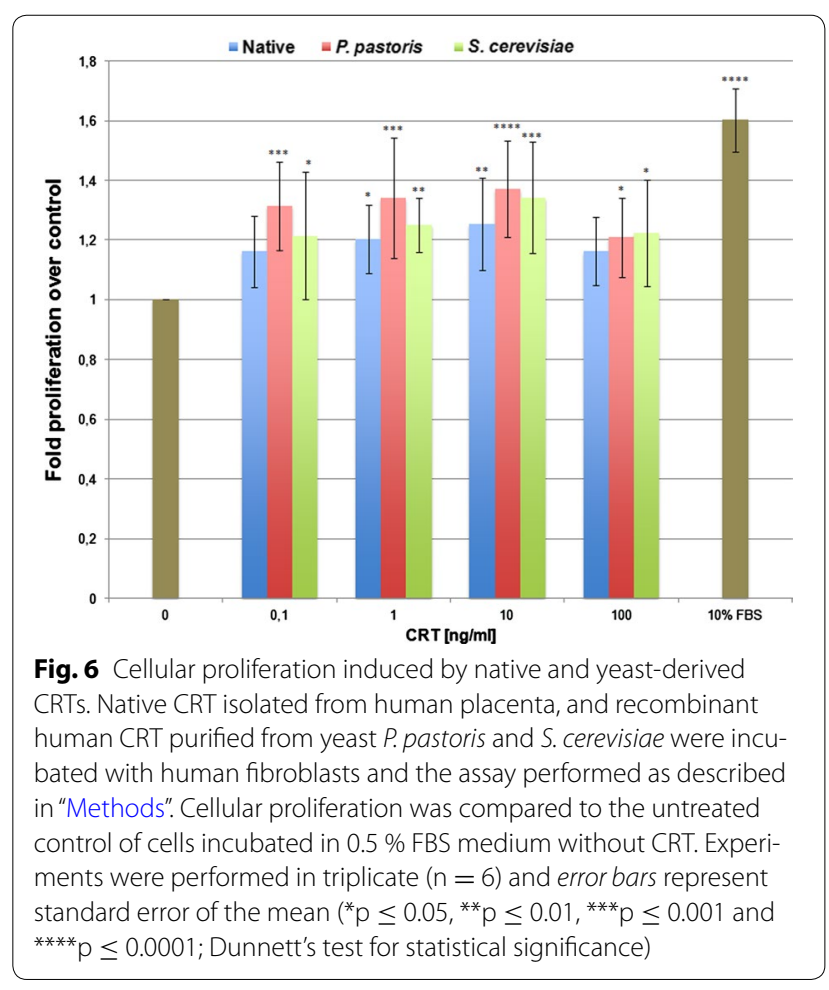

shown. In Fig. 6, this downward trend at $100 \mathrm{ng} / \mathrm{ml} \mathrm{CRT}$ was not statistically significantly different than CRT at $10 \mathrm{ng} / \mathrm{ml}$.

Using the scratch plate method as an in vitro wound healing assay, after $24 \mathrm{~h}$ of treatment, 75-95\% wound closure was achieved with all CRT proteins with a peak concentration of $1.0 \mathrm{ng} / \mathrm{ml}$ compared to the $0.5 \%$ FBS untreated control, which showed $53 \%$ closure at $24 \mathrm{~h}$ (Fig. 7a). Specifically, at this peak concentration, a statistically significant induction of wound closure by native CRT of $81.3 \%(\mathrm{p} \leq 0.05)$ and CRT produced by $P$. pastoris of $94.6 \%(\mathrm{p} \leq 0.001)$ over the untreated control was obtained $(n=1)$. Whereas statistical significance in induction of wound closure at this concentration was not reached by CRT from $S$. cerevisiae, there was no difference among the three CRTs at $1.0 \mathrm{ng} / \mathrm{ml}$. To test the sensitivity of CRT responsiveness in stimulating migration as measures by wound closure on the scratch, the plates were analyzed at $6 \mathrm{~h}$ post-treatment. As shown in Fig. $7 \mathrm{~b}$, there was a statistically significant induction of wound closure for native and $S$. cerevisiae-derived CRTs at both 1.0 and $10 \mathrm{ng} / \mathrm{ml}(\mathrm{n}=2)$. At the peak concentration of $10 \mathrm{ng} / \mathrm{ml} \mathrm{CRT,} \mathrm{native} \mathrm{and} \mathrm{S.} \mathrm{cerevisiae-secreted}$ CRTs stimulated wound closure at $9.3 \%(\mathrm{p} \leq 0.01)$ and $8.7 \%(\mathrm{p} \leq 0.05)$, respectively over the untreated control of $5.5 \%$ closure. There weren't any statistically significant differences among all CRTs at any dose. Notably, the peak of activity in induction of wound closure was similar with 

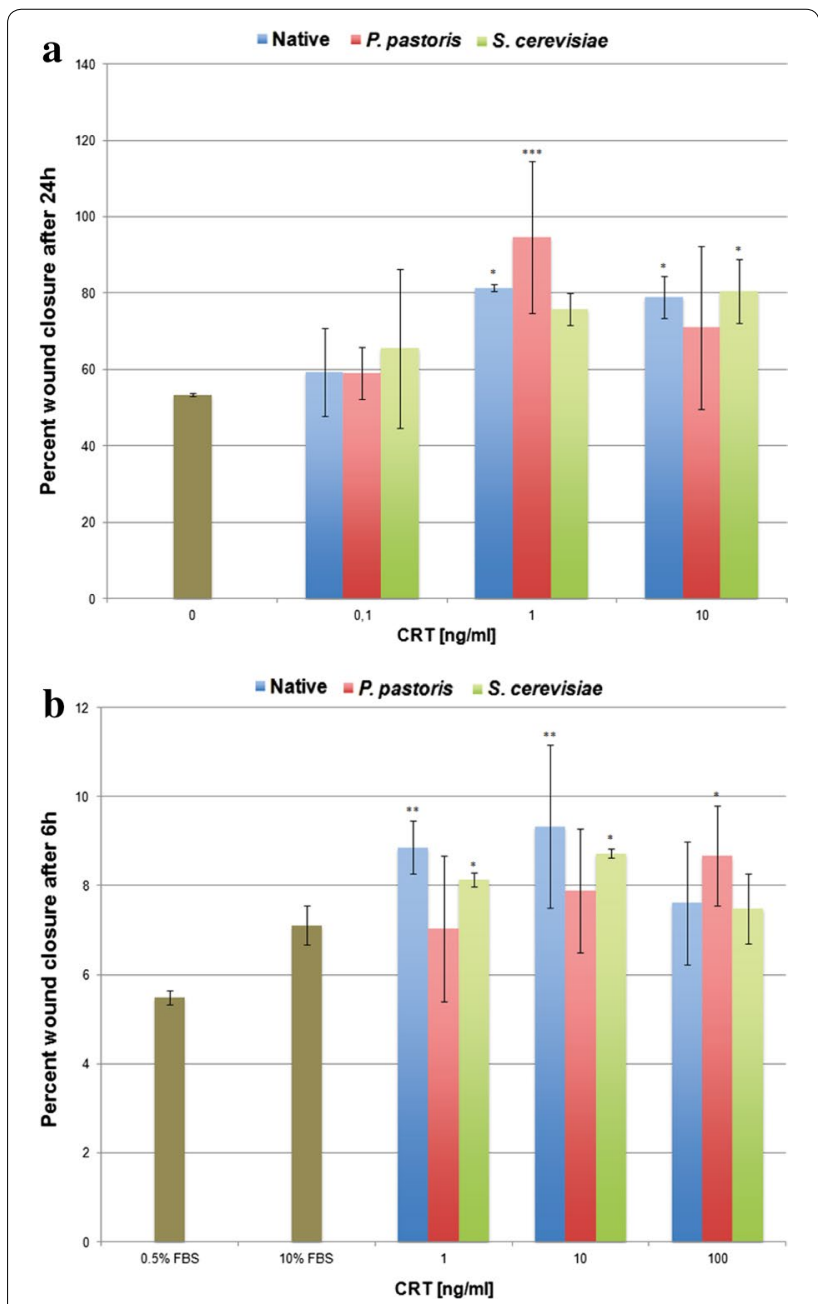

Fig. 7 Migration of human dermal fibroblasts induced by native and yeast-derived human CRTs. a Primary human dermal fibroblasts were plated, wounded, treated with increasing doses of native placental or recombinant human CRTs $(0.1-10 \mathrm{ng} / \mathrm{ml})$ and assayed for wound closure after $24 \mathrm{~h}$, as described in methods. Experiments were performed in triplicate. Error bars represent standard deviation $(n=1)$. b Primary human dermal fibroblasts were plated, wounded, treated with increasing concentrations of CRT (1-100 $\mathrm{ng} / \mathrm{ml})$, and assayed for wound closure at $6 \mathrm{~h}$. Experiments were performed in triplicate $(n=2)$. Error bars represent standard error of the mean. A Dunnett's test for statistical significance was performed $\left({ }^{*} p \leq 0.05,{ }^{* *} p \leq 0.01\right.$, and ${ }^{* * *} p \leq 0.001$ )

native CRT compared to the two yeast-derived recombinant CRTs suggesting that the functional integrity of yeast-derived CRT was preserved. As described above, the downward trend in activity at $100 \mathrm{ng} / \mathrm{ml}$ was obtained previously $[13,14]$ and likely represents receptor saturation at higher concentrations. Whereas receptor signaling via the LRP1 has been shown for migration [34], which might be operating in the scratch plate assay, the receptor that mediates proliferation is unknown.
Earlier we reported that ATPase activity of yeastsecreted human GRP78/BiP protein exceeded the activity of $E$. coli-derived recombinant human BiP threefold [21], whereas yeast-secreted human ERp57 catalyzed the reduction of insulin at a faster rate than analogous recombinant human protein expressed in E. coli [22]. However, comparative biological activities to native human proteins were precluded since native protein was not available. The use of native CRT protein isolated from human placenta herein afforded the opportunity to optimally compare the yeast-secreted recombinant protein with purified native human CRT. Similar functional activity of native CRT and recombinant CRT strongly suggest that the synthesized and secreted recombinant CRT should have the same effect on wound healing in vivo, as cellular migration and proliferation are critical functions that enable the wound repair process [13]. As animal studies showed that topical CRT has the potential to be used as an effective therapeutic agent for chronic wounds, including poor healing diabetic wounds [14], the molecular identity between native and yeast-derived CRTs underscores the utility of recombinant CRT secreted from yeast as having clinical and commercial value for wound healing. As the protein consists of the same amino acid sequence, CRT should not be immunogenic as a side effect of treatment.

\section{High-level secretion of recombinant human CRT by fed-batch fermentation of $P$. pastoris}

Development of biopharmaceuticals requires the biosynthesis process to be fully controlled and industrially relevant. P. pastoris is known as a highly efficient expression system with well-developed high culture density fermentation protocols. Therefore, we performed synthesis of recombinant secreted human CRT using cultivation of $P$. pastoris in a bioreactor and show the results, which can be adapted for the production of human CRT protein at an industrial scale.

A fed-batch cultivation of $P$. pastoris clone CPp9 was carried out in a 51 bioreactor Biostat A plus using a fourstep growth protocol, consisting of glycerol batch, glycerol fed-batch, transition phase and methanol fed-batch phases. The protocol for the fermentation was adapted from Tolner et al. [35] with several modifications to avoid proteolytic degradation of secreted human CRT. The glycerol batch phase was carried out at $28^{\circ} \mathrm{C}$, instead of $30{ }^{\circ} \mathrm{C}$, lasted $28 \mathrm{~h}$, and dry cell weight (DCW) reached 33.5 g/l (Fig. 8). Subsequently, the glycerol batch phase $\mathrm{pH}$ of the medium was increased to 7 and the glycerol fed-batch phase was initiated by adding $50 \%$ glycerol and temperature was maintained at $28{ }^{\circ} \mathrm{C}$. Following testing the susceptibility of human CRT to proteases released into the culture broth by P. pastoris, $\mathrm{pH} 7$ was found to 


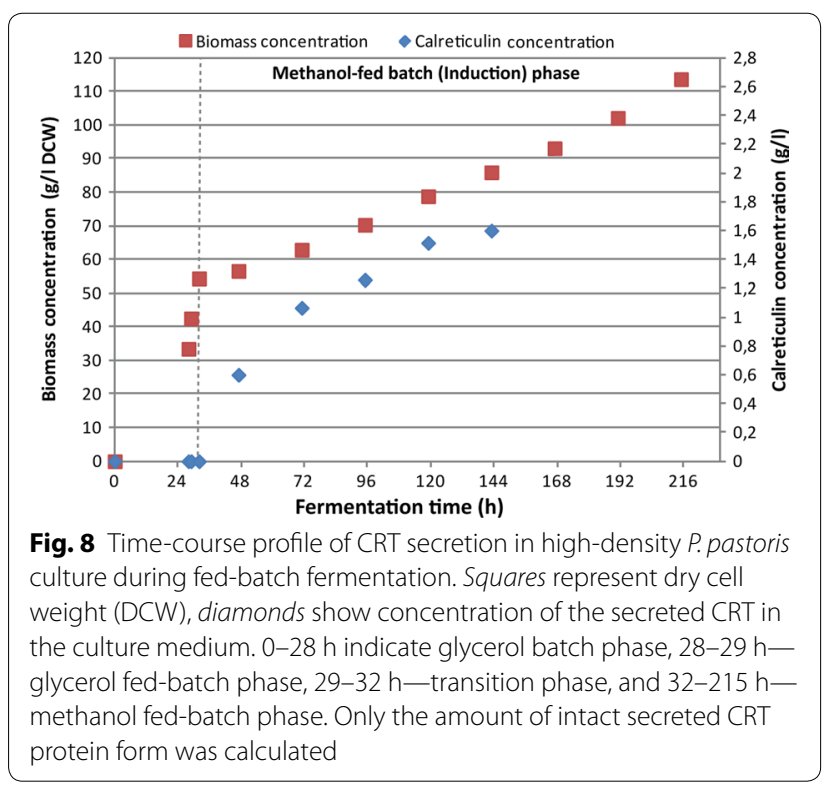

ensure optimal stability of the protein (data not shown). After $1 \mathrm{~h}$ of glycerol-fed batch, DCW reached $42.5 \mathrm{~g} / \mathrm{l}$ (Fig. 8). The transition phase was started by adding $0.2 \%$ methanol, ramping down the rate of glycerol feeding to $0 \mathrm{ml} / \mathrm{l} / \mathrm{h}$, and also decreasing the culture broth temperature to $20{ }^{\circ} \mathrm{C}$. This temperature favoured CRT stability due to decreased release of proteases by yeast cells. After the transition phase, DCW reached $54.4 \mathrm{~g} / \mathrm{l}$ (Fig. 8) and cells adapted to methanol and lower temperature. $20{ }^{\circ} \mathrm{C}$ temperature was maintained throughout the methanol fed-batch phase. Because it was shown [36] that methanol consumption rate at lower temperatures $\left(15{ }^{\circ} \mathrm{C}\right)$ is decreased by $25 \%$, methanol feed rate during induction phase was decreased by $50 \%$ to $3.8 \mathrm{ml} / \mathrm{l} / \mathrm{h}$ compared to the feed rate of $7.5 \mathrm{ml} / \mathrm{l} / \mathrm{h}$ recommended by Tolner et al. [35]. Notably, decreasing the methanol feed rate only by $25 \%$ to $5.6 \mathrm{ml} / \mathrm{l} / \mathrm{h}$ led to increased proteolytic degradation of human CRT, thus $3.8 \mathrm{ml} / \mathrm{l} / \mathrm{h}$ methanol feed rate was found to be optimal for biomass and intact protein accumulation (Fig. 8). However, after $135 \mathrm{~h}$ induction (167 h fermentation time), secreted human CRT showed signs of degradation and after $183 \mathrm{~h}$ induction $(215 \mathrm{~h}$ fermentation time), degradation was severe (Fig. 9). It was therefore determined that the optimal induction time was $111 \mathrm{~h}$ (143 h fermentation time) when secreted human CRT concentration reached $1.6 \mathrm{~g} / \mathrm{l}$ and DCW was $85.9 \mathrm{~g} / \mathrm{l}$ (Figs. 8, 9). Specific growth rate on methanol was $0.0042 \mathrm{~h}^{-1}$.

\section{Secretion efficiency of human CRT in yeast}

To explore the reasons for high-level secretion of human CRT, we determined its secretion efficiency by the same

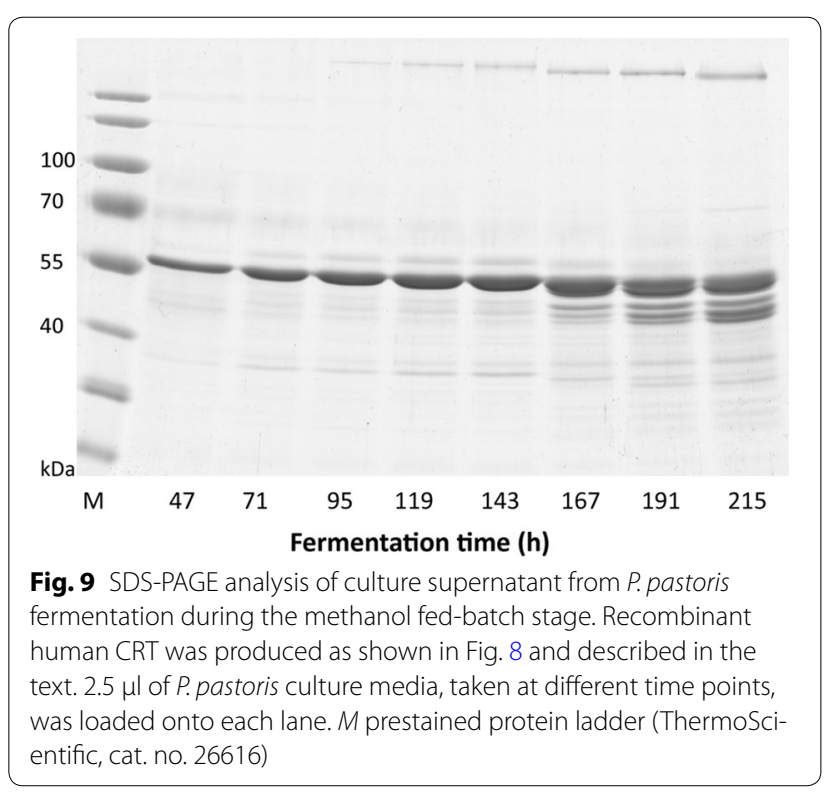

method as previously reported for human GRP78/BiP and ERp57 in yeast [21, 22]. SDS-PAGE analysis of crude lysates from S. cerevisiae harbouring pFDC-CRT plasmid revealed a more intense band corresponding to the $\mathrm{MW}$ of recombinant human CRT compared to control cells carrying pFDC vector (Fig. 10a, lanes pFDC and pFDCCRT). The band of comparable intensity and corresponding to the MW of CRT protein was also observed in crude lysate from $P$. pastoris cells, which expressed CRT by high-density fermentation in a bioreactor (Fig. 10a, lane PpB-CRT). Quantitative Western blots using antibodies against human CRT protein showed that intracellular CRT constituted approximately $1.1 \%$ of total cell protein in S. cerevisiae (Fig. 10b, c). Evaluation of protein amount according to cell biomass produced from $1 \mathrm{l}$ of S. cerevisiae culture revealed that $\sim 30 \%$ of CRT was expressed internally $(\sim 25 \mathrm{mg})$ and $\sim 70 \%$ was secreted into the culture medium ( $\sim 60-65 \mathrm{mg})$. Although there was a higher amount of intracellular CRT in P. pastoris constituting approximately $2 \%$ of total cell protein $(\sim 1.9$ and $\sim 2.1 \%$ determined in two different experiments shown in Fig. 10b, c, respectively), the efficiency of CRT secretion reached $\sim 80 \%$ due to the higher amount of secreted protein in the same culture volume $(\sim 1.6 \mathrm{~g}$ of secreted and $\sim 400 \mathrm{mg}$ of internally expressed CRT). Secretion efficiencies of different human ER chaperones in S. cerevisiae can be directly compared, because we used the same expression procedure for CRT, GRP78/BiP and ERp57. Efficiency of CRT secretion ( 70 \%) was considerably higher than either that of GRP78/BiP ( 30\%) [21] or ERp57 ( 20 \%) [22]. It suggests that CRT is less efficiently retained inside the yeast cells compared to the other two 


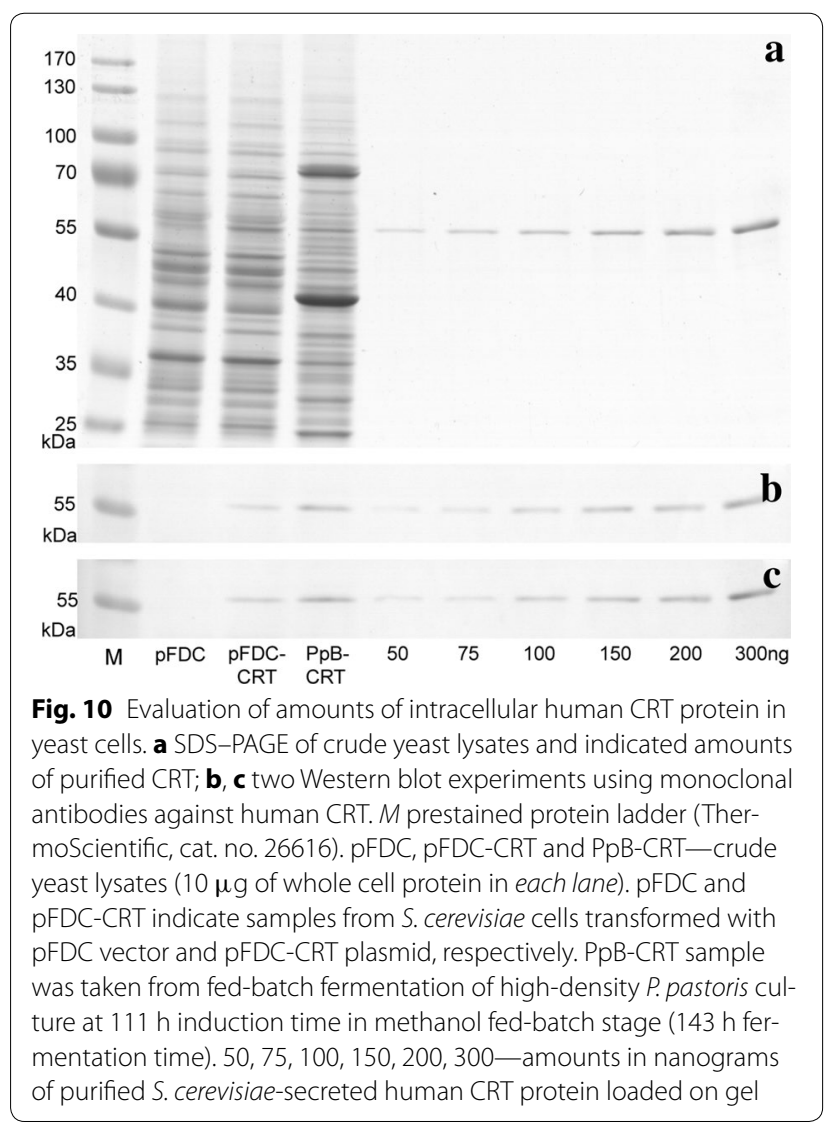

human ER chaperones. Overall higher expression level of CRT could only partially contribute to observed higher CRT levels in $S$. cerevisiae culture media. Total CRT amount was $85-90 \mathrm{mg} / \mathrm{l}$ compared to $50-60 \mathrm{mg} / \mathrm{l}$ of the other two human ER chaperones (i.e. 1.5-1.8 fold higher, when secreted protein amounts differ four- to fivefold), but there were even lower CRT amounts inside the cells ( $25 \mathrm{mg} / \mathrm{l}$ vs. $35-50 \mathrm{mg} / \mathrm{l}$ for BiP and ERp57). Thus, less efficient intracellular retention of CRT is evident from this data and it seems to be related to intrinsic properties of the protein. It should be noted that all three recombinant human ER chaperones contained an ER-retention/ retrieval signal (KDEL for CRT and BiP, or QDEL for ERp57), which did not prevent secretion in yeast. Replacing ER retention signal to yeast preferable ER retention signal HDEL did not suppress the secretion of these three proteins (our unpublished data). Moreover, overload of the yeast ER retrieval machinery as the reason for secretion of human ER chaperones can also be omitted, because overexpression of yeast Kar2 protein with native HDEL ER retrieval sequence using the same pFDC vector did not lead to the secretion of this protein [21]. These results indicate that the mechanism(s) involved are currently elusive and deserve further investigation. We propose that one of the reasons might be limited accessibility of the ER retrieval signals of human ER chaperones in the yeast cells. For example, ER calcium depletion was shown to induce CRT secretion [18], whereas free $\mathrm{Ca}^{2+}$ in the lumen of the yeast ER is 10-100 times lower than that of mammalian ER $[37,38]$. Such distinctly different characteristics may result in a CRT conformation, which limits accessibility of the KDEL retrieval signal and favours protein secretion outside of the yeast cells. Nevertheless, this issue requires additional studies.

\section{Significance and applicability of the results}

With a growing demand for human CRT biotherapeutics, we introduce yeast $S$. cerevisiae and P. pastoris as excellent hosts for easily purified, high-level production of human CRT. Here we demonstrated that the native signal sequence of human CRT precursor is correctly cleaved and directs secretion in yeast cells. High-level secretion of human CRT using fed-batch fermentation of highdensity $P$. pastoris culture in a bioreactor allowed efficient production of secreted CRT protein in grams per liter scale. To the best of our knowledge, this is one of the highest secretion levels achieved using native human protein signal sequences in yeast. Comparable results after optimization were achieved only with human serum albumin (HSA) [39]. Our data suggest that molecular integrity and functional activity of yeast-secreted recombinant CRT is identical to native CRT protein from human placenta. From these results, we can extrapolate that CRT secreted by yeast should be inherently biologically active in any functional in vitro and in vivo acitivity (harboured by native CRT) with applicability to the development of new biopharmaceuticals such as has been shown for normal and diabetic wound healing [13, 14]. Moreover, it was recently shown that this same yeastsecreted CRT can also be used as a cancer treatment adjuvant in combination with photodynamic therapy [40]. Yeast-secreted recombinant protein may be advantageous in such applications, because it corresponds to the native analogue insofar as possible. Furthermore, yeast-derived heterologous proteins are free of toxic contaminations and are excellent tools for developing biopharmaceuticals, because $S$. cerevisiae is acknowledged as a GRAS (generally regarded as safe) organism. Therefore, secretory expression of native recombinant human CRT in yeast could be exploited for efficient and safe production of potential therapeutic agents.

\section{Conclusions}

Our results show that yeast is an excellent host for efficient and industrial scale production of native recombinant human CRT. Yeast cells are able to recognize and correctly process the native signal sequence of human 
CRT precursor. Yeast secretes mature CRT protein into the culture medium, instead of retaining the protein in the ER. Unusual high-level secretion enabled CRT production in grams per liter scale with a simple and costeffective purification scheme. Recombinant CRT secreted by yeast appears seemingly identical to the native protein from human placenta with respect to its molecular integrity and functional activity in vitro. The yeast expression and purification systems for human CRT offer a new way of producing large quantities of human protein for therapeutic application.

\section{Methods}

\section{Plasmids, yeast strains, transformation and selection of transformants}

DNA manipulations were performed according to standard procedures [41], bacterial recombinants were screened in Escherichia coli $\mathrm{DH} 5 \alpha \mathrm{F}^{\prime}$ cells. A cDNA encoding full-length human calreticulin precursor (GenBank Acc. no. M84739) was amplified from a commercial human adult liver cDNA library (Clontech) by PCR using specific oligonucleotide primers CRTF (gta tct aga aca atg ctg cta tcc gtg ccg ttg) and CRTR (cag tct aga cta cag ctc gtc ctt ggc ctg), digested with restriction endonuclease (RE) XbaI (recognition sites in sequences of primers are indicated in bold) and cloned into yeast expression vectors pFDC [20] and pPIC3.5K (Invitrogen) into RE sites XbaI and AvrII under the control of $S$. cerevisiae PGK1 or P. pastoris AOX1 promoters, respectively. Cloned $C R T$ gene coding sequence (beginning from start codon ATG and ending with STOP codon TAG) was verified by DNA sequencing and generated plasmids pFDCCRT and pPIC3.5K-CRT were used for transformation of yeast S. cerevisiae strain AH22 (MATa leu2 his4) and P. pastoris strain GS115 (his4), respectively. S. cerevisiae transformants were selected by resistance to formaldehyde [21] and harboured multicopy autonomously replicating plasmid pFDC-CRT, whereas multicopy P. pastoris transformants were selected by resistance to G418 [42] and $\mathrm{Mut}^{+}$clone CPp9 with the most efficient secretion of CRT protein was chosen for further experiments. Both yeasts were used for expression of the full length CRT protein precursor including the native $\mathrm{N}$-terminal signal peptide.

\section{Protein expression in shake-flask cultivations and purification of recombinant CRT from yeast culture media}

Saccharomyces cerevisiae cells harbouring plasmid pFDC-CRT were grown for $36 \mathrm{~h}$ in YEPD (yeast extract $1 \%$, peptone $2 \%$, dextrose $2 \%$ ) medium. P. pastoris transformants with multicopy integrations of expression vector pPIC3.5K-CRT were initially grown in Ygly medium containing glycerol as carbon source (yeast extract $1 \%$, peptone $2 \%$, glycerol $1 \%$, biotin $2 \times 10^{-5} \%$ ) for $24 \mathrm{~h}$ up to OD of 18-20, and culture medium was changed to Ymet containing methanol (yeast extract $1 \%$, peptone $2 \%$, methanol $1 \%$, biotin $2 \times 10^{-5} \%$ ) for induction of CRT cDNA expression. Then flasks were further incubated in the shaker at $30{ }^{\circ} \mathrm{C}, 220 \mathrm{rpm}$ for $120 \mathrm{~h} .1 \%$ of methanol was added every $8 \mathrm{~h}$ to maintain protein expression. Both $P$. pastoris and $S$. cerevisiae cultures were centrifuged at $10,000 \times g$ for $10 \mathrm{~min}$ at $4{ }^{\circ} \mathrm{C}$. Supernatants were collected and stored on ice. Protocol for CRT purification from culture media was the same for both yeasts.

Yeast culture medium was microfiltered through 1.6 $\mu \mathrm{M}$ (Sartorius Stedim Biotech, cat. no. FT-3-1101047), $0.45 \mu \mathrm{M}$ (Sartorius Stedim Biotech, cat. no. 1540647) and $0.2 \mu \mathrm{M}$ (Sartorius Stedim Biotech, cat. no. 15407-47-MIN) filters using a Pressure Filter Holder (Sartorius Stedim Biotech, cat. no. 16249) and a vacuum pump. After microfiltration, proteins from the culture medium were concentrated and transferred into the binding buffer $(20 \mathrm{mM}$ L-histidine, $100 \mathrm{mM} \mathrm{NaCl}$, $\mathrm{pH}$ 5.5) through tangential ultrafiltration using cassettes with 100 kDa cut-off membranes (Sartorius Stedim Biotech, cat. no. VF20P4) and a peristaltic pump. Further, proteins were loaded onto the column packed with Q Sepharose FastFlow resin (GE Healthcare, cat. no. 17-0510-10) equilibrated in the same buffer. The column was washed with 5 volumes of binding buffer and bound proteins were eluted with a $\mathrm{NaCl}$ concentration gradient (100-500 mM). CRT was eluted in a single peak with approximately $250 \mathrm{mM} \mathrm{NaCl}$. Elution fractions containing purified recombinant protein were pooled and buffer was exchanged to CRT storage buffer (20 mM Tris- $\mathrm{HCl}, 150 \mathrm{mM} \mathrm{NaCl}, 3 \mathrm{mM} \mathrm{CaCl}_{2}, \mathrm{pH}$ 7.5) using Sephadex G25 column. Protein was stored frozen at $-70{ }^{\circ} \mathrm{C}$.

\section{Purification of native CRT from human placenta}

Human placentas were donated for research with written consent from women who had given birth to healthy children at Rigshospitalet, Copenhagen. At the Statens Serum Institut they were used anonymously for purification of CRT. Human placental CRT was purified as described previously [26]. Briefly, a placenta was homogenized twice in $20 \mathrm{mM}$ BisTris, $1 \mathrm{mM} \mathrm{CaCl}_{2}, \mathrm{pH} 7.5$ with protease inhibitors (Complete) and with intermittent centrifugations. The residue was then extracted twice in $20 \mathrm{mM}$ BisTris, $1 \mathrm{mM} \mathrm{CaCl}_{2}$, pH 7.5, 1 \% Triton X-114 to release ER luminal proteins. Membrane proteins were removed by phase separation at $37^{\circ} \mathrm{C}$ and large proteins removed from the water phase by ammonium sulphate precipitation $(337 \mathrm{~g} / \mathrm{l})$ overnight at $5{ }^{\circ} \mathrm{C}$. The supernatant 
was ultradiafiltrated against $20 \mathrm{mM}$ Tris, $1 \mathrm{mM} \mathrm{CaCl}$, pH 7.5 and chromatographed on a Q Sepharose column equilibrated in the same buffer and eluted with a linear $\mathrm{NaCl}$ gradient. CRT-containing fractions were pooled and concentrated to $1 \mathrm{mg} / \mathrm{ml}$ in $20 \mathrm{mM}$ Tris/ $\mathrm{HCl}, \mathrm{pH}$ 7.5 using a Centriprep filter. Purified placental CRT was stored frozen at $-20{ }^{\circ} \mathrm{C}$.

\section{Partial proteolysis of CRT with trypsin in the presence of calcium}

Partial digestion of CRT with trypsin was performed according to previously described procedures [26, 31]. Purified yeast-secreted CRT was diluted to $1 \mathrm{mg} / \mathrm{ml}$ concentration in storage buffer containing $3 \mathrm{mM} \mathrm{CaCl}_{2}$. To avoid influence of different storage buffers, native placental CRT was also transferred to storage buffer with $3 \mathrm{mM} \mathrm{CaCl}_{2}$ as for recombinant CRTs, and diluted to the same concentration. Digestion was performed at $37^{\circ} \mathrm{C}$ in $50 \mu \mathrm{l}$ volume by adding $1 \mu \mathrm{l}$ of $0.5 \mathrm{mg} / \mathrm{ml}$ trypsin [ratio of CRT:trypsin was 100:1 (w/w)]. In a control tube, calcium was removed by adding EGTA to $5 \mathrm{mM}$ concentration. The reaction was stopped after $60 \mathrm{~min}$, by adding $1 \mathrm{mM}$ PMSF. The samples were boiled, loaded onto the gels, and SDS-PAGE was performed.

\section{Function of yeast-derived calreticulin: cellular migration and proliferation assays}

Cell proliferation An in vitro assay for cellular proliferation was performed as previously described $[13,14]$. Primary low passage human dermal foreskin fibroblasts (CCD 1070SK; American Type Culture Collection, Manassas, VA, USA), grown in complete Eagle's minimal essential medium (MEM; Gibco/Life Technologies, Carlsbad, CA, USA) containing $10 \%$ fetal bovine serum (FBS), $2 \mathrm{mM}$ glutamine (Mediatech, Manassas, VA, USA), $1.0 \mathrm{mM}$ sodium pyruvate (Gibco) and antibiotics, were seeded at $2 \times 10^{3}$ cells per well in 96 well plates and grown to $50 \%$ confluency $(24 \mathrm{~h})$. Subsequently, the cells were synchronized in media containing $0.5 \%$ FBS for $24 \mathrm{~h}$ and treated with increasing concentrations of CRT $(0-100 \mathrm{ng} / \mathrm{ml})$ from placenta, or S. cerevisiae or P. pastoris for $72 \mathrm{~h}$. CRT protein concentrations were determined by microBCA assay to standardize that equal amounts of each CRT were used. The assay was performed in triplicate for each test parameter. Media with $0.5 \%$ FBS and $10 \%$ FBS served as a negative and positive controls, respectively. Proliferation was determined by an MTS assay (CellTiter96 assay, G3580, Promega, Madison, WI, USA). Cells were incubated in MTS solution for $1 \mathrm{~h}$ and absorbance was measured at $490 \mathrm{~nm}$ (BioRad ELISA reader). The data are expressed as fold proliferation over untreated control $(n=6$ experiments).
Cell migration The effect of native human placental and yeast-derived human CRT on cellular migration was assessed by the classic in vitro wound healing scratch plate assay, as described [13, 14]. Human dermal fibroblasts in complete MEM containing $10 \%$ FBS were seeded at $2 \times 10^{4}$ cells per well in 24 well plates and grown to 70-80\% confluency. The cells were switched to media containing $0.5 \%$ FBS for $24 \mathrm{~h}$, and then wounds were created down the center of each well by scratching with a $200 \mu$ pipette tip, and the loose cells removed by washing with PBS. The edges of the wounds were denoted with a fine-tipped marker on the underside of the plate. The cells were treated for 6 or $24 \mathrm{~h}$ with increasing concentrations of CRT protein in $0.5 \%$ FBS media. 0.5 and $10 \%$ FBS served as negative and positive controls, respectively. Migration was terminated by incubating the cells with $0.025 \%$ Coomassie blue in $10 \%$ acetic acid, $45 \%$ methanol for 10 min followed by washing twice with PBS. The plates were viewed under an inverted light microscope (Axiovert s-100; Zeiss, Thornwood, NY, USA) and images captured and cell migration calculated by measuring the area (pixels) not occupied by cells (i.e., open area remaining) to the area of the original scratch at time 0 using Metamorph software version 7.1.3.0 (Molecular Probes, Eugene OR, USA). The plates were normalized for cell density at a part of the plate distal to the scratch. The data are expressed as per cent wound closure ( 0 time compared to 6 or $24 \mathrm{~h}$ later) and the averages for each test parameter subjected to analysis of variance (ANOVA). Statistical significance for both proliferation and wound closure assays were performed using GraphPad Prism software (version 6). A twoway ANOVA followed by a Dunnett post hoc test by comparing each treatment value with $0.5 \% \mathrm{FBS}$ as the untreated control; statistical significance was $(p<0.05)$. The experiments were performed in triplicate $(n=2$ experiments at $6 \mathrm{~h}$ and $\mathrm{n}=1$ at $24 \mathrm{~h}$ ).

\section{High cell density fed-batch fermentation of recombinant $P$. pastoris}

For this study, selected $\mathrm{Mut}^{+}$phenotype $P$. pastoris GS115 transformant strain CPp9 carrying multiple copies of human $C R T$ gene under the control of $A O X 1$ promoter, was used. A $200 \mathrm{ml}$ culture for inoculation of bioreactor was prepared in two stages as described previously [35]. First, a 20-ml primary seed YEPD medium was prepared using $200 \mu \mathrm{l}$ of the user seed lot which was grown at $28{ }^{\circ} \mathrm{C}$ in an orbital shaker (New Brunswick Innova 40R) at $220 \mathrm{rpm}$ for $24 \mathrm{~h}$. This primary seed medium was used to inoculate a $200 \mathrm{ml}$ secondary seed medium, containing fermentation media, to $0.1 \mathrm{OD}$ that was grown for 16-18 h to 4-6 OD under the same conditions, to serve 
as inoculum for the bioreactor culture. Cultures were grown in baffled flasks whose volumes were $5 \times$ the culture volume to permit adequate aeration.

High-cell density fed-batch cultivation was performed as described previously [35] with several exceptions. Cultivation was carried out in a 51 BIOSTAT-A plus (Sartorius Stedim Biotech) bioreactor interfaced with MFCS/ DA software for data acquisition and control. A $200 \mathrm{ml}$ inoculum, prepared as described above, was transferred to the bioreactor containing $1.8 \mathrm{l}$ fermentation media. The fermentation media contained per liter: glycerol, $63 \mathrm{~g}$; potassium sulfate, $14.67 \mathrm{~g}$; calcium sulfate, $0.9 \mathrm{~g}$; magnesium sulfate hepta-hydrate, $11.67 \mathrm{~g}$; trace metal solution (PTM1), $4 \mathrm{ml}$; ammonium sulfate, 9 g; hexametaphosphate, $25 \mathrm{~g}$. The PTM1 solution contained per liter: sodium iodide, $0.08 \mathrm{~g}$; manganese sulfate mono-hydrate, $3.0 \mathrm{~g}$; sodium molybdate di-hydrate, $0.2 \mathrm{~g}$; boric acid, $0.02 \mathrm{~g}$; zinc chloride, $20.0 \mathrm{~g}$; ferric sulfate hepta-hydrate, 65.0 g; cupric sulfate penta-hydrate, 6.0 g; biotin, $0.2 \mathrm{~g}$; and sulfuric acid, $5.0 \mathrm{ml} .0 .2 \mathrm{ml}$ of antifoam (Antifoam 204, SigmaAldrich) per 11 media was added manually before inoculation to control foaming in the bioreactor. Aeration rate of $1 \mathrm{vvm}$ was constant throughout the whole process. The dissolved oxygen (DO) throughout the whole process was controlled at $30 \%$ saturation using an automatic DO control by agitation cascade between 410 and $750 \mathrm{rpm}$ and oxygen supplementation. When a maximum $750 \mathrm{rpm}$ was reached, pure oxygen was supplied through a gas blender to control dissolved oxygen at $30 \%$ saturation.

Temperature during glycerol batch phase was maintained at $28{ }^{\circ} \mathrm{C}$ and $\mathrm{pH}$ at 5.0 with $28 \%$ (v/v) $\mathrm{NH}_{4} \mathrm{OH}$. After consumption of glycerol, indicated by an increase of the DO concentration, glycerol-fed batch phase was initiated. Temperature during glycerol-fed batch phase was maintained at $28{ }^{\circ} \mathrm{C}$ and $\mathrm{pH}$ at 7.0. $50 \%$ glycerol (v/v) with PTM1 was fed at $20 \mathrm{ml} / \mathrm{l} / \mathrm{h}$ for $1 \mathrm{~h}$ before being ramped down to $0 \mathrm{ml} / \mathrm{l} / \mathrm{h}$ at a uniform rate over a 3-h period. The ramping down of glycerol marked the beginning of the transition phase and $2 \mathrm{ml} / \mathrm{l}$ of methanol was added to the bioreactor to allow the cells to adjust to methanol. Temperature during transition phase was ramped down to $20{ }^{\circ} \mathrm{C}$ and $\mathrm{pH}$ was maintained at 7.0. After transition phase methanol-fed batch phase (production of recombinant CRT) was initiated by the addition of methanol at a $2 \mathrm{ml} / \mathrm{l} / \mathrm{h}$ rate which was increased to $3.8 \mathrm{ml} / \mathrm{l} / \mathrm{h}$ at a uniform rate over a $6 \mathrm{~h}$ period and $3.8 \mathrm{ml} / \mathrm{l} / \mathrm{h}$ methanol feed rate was maintained during whole methanol-fed batch. Temperature during methanol-fed batch phase was maintained at $20^{\circ} \mathrm{C}$ and $\mathrm{pH}$ at
7.0. For DCW determination, cell pellets were washed once with distilled water and incubated in an open tube to a constant weight at $80^{\circ} \mathrm{C}$.

\section{Miscellaneous}

Tryptic peptide mass fingerprinting was carried out at the Proteomics Center in the Institute of Biochemistry of Vilnius University (Lithuania). S. cerevisiae-secreted CRT was analyzed by MALDI-TOF/TOF tandem MS/ MS (mass spectrometry) as described previously [43]. Trypsin digestion of P. pastoris-secreted CRT was done according to a modified FASP protocol as described by Wisniewski et al. [44]. The nano-LC was coupled online with an HDMS Synapt G2 mass spectrometer (Waters Corporation, UK). LC-MS data were collected using data independent acquisition (DIA) mode $\mathrm{MS}^{\mathrm{E}}$ in combination with online ion mobility separation.

$\mathrm{N}$-terminal sequencing of yeast-secreted human CRT protein by Edman degradation was performed by AltaBioscience.

The molecular masses of proteins were measured by ESI-MS using an Agilent Q-TOF 6520 mass spectrometer.

Native PAGE was performed exactly as described previously [21], whereas blue native PAGE was carried out according to Niepmann and Zheng [45].

Protein concentrations were determined by Roti-Nanoquant Protein-assay (Carl Roth Gmbh., cat. no. K880) using BSA for calibration curve.

Densitometric analysis of SDS-PAGE gels scanned with ImageScanner III (GE Healthcare) was performed with ImageQuant TL (GE Healthcare) software using default settings. For quantitative analysis of secreted CRT, the culture medium was separated from cells by centrifugation, directly mixed with equal amount of $2 \times$ SDSPAGE sample buffer [46], boiled and loaded onto gel lanes. Amounts of secreted CRT in culture medium were determined by comparison to a range of known amounts of BSA (Fermentas product \#B14 was used) in a linear dynamic range $\left(R^{2}>0.99\right)$ of Coomassie-stained protein bands in SDS-PAA gels. To determine CRT purity in crude yeast culture media, total secreted yeast proteins were concentrated by precipitation and yeast protein impurities were evaluated by SDS-PAGE.

Precipitation of proteins from yeast culture medium for SDS-PAGE analysis was performed based on a defined methanol-chloroform-water mixture, as described earlier [47].

Mouse monoclonal anti-CRT antibody [FMC 75] was purchased from Abcam (cat. no. ab22683-100). 


\section{Additional files}

Additional file 1. Different secretion levels of human ER chaperones in yeast. SDS-PAGE (A) and Western blot (B) analysis of $40 x$ concentrated culture media of yeast $\mathrm{S}$. cerevisiae $\mathrm{AH} 22$ cells transformed with empty plasmid pFDC (lane 1) or producing human chaperones BiP, CRT and ERp57 (lanes 2, 3 and 4, respectively). Anti-GRP78 BiP antibody (ab21685), mAb anti-CRT FMC 75 and ERp57 (MaP.ERp57) antibody (sc-23886) were used in Western blots to detect recombinant BiP, CRT and ERp57, respectively.

Additional file 2. Elution profiles of recombinant CRT in anion-exchange chromatography. Separation of CRT from S. cerevisiae (A and B) was performed on a pre-packed $5 \mathrm{ml}$ Q-Sepharose column (GE LifeSciences cat. no. 17-5156-01), equilibrated with $20 \mathrm{mM} \mathrm{L-His,} \mathrm{pH} \mathrm{5.5,} 100 \mathrm{mM} \mathrm{NaCl}$ buffer, in 15 column volumes linear gradient from $100 \mathrm{mM}$ to $500 \mathrm{mM}$ $\mathrm{NaCl}$. Separation of CRT from P. pastoris (C and D) was performed on a 15 $\mathrm{ml}$ Q-Sepharose sorbent (GE LifeSciences cat. no. 17-0510-10) packed into the XK 16/20 column (GE Lifesciences, cat. no. 28-9889-37), equilibrated with $20 \mathrm{mM}$ L-His, pH 5.5, $100 \mathrm{mM} \mathrm{NaCl}$ buffer, in 10 column volumes linear gradient from 100 to $500 \mathrm{mM} \mathrm{NaCl}$. Elution profiles (A and C) and SDS-PAGE gels of corresponding fractions ( $B$ and $D$ ) are shown. Dashed lines define fractions that were pooled and used for further experiments with purified protein

Additional file 3. Western blotting analysis of recombinant and native human CRTs. The same samples were analysed by SDS-PAGE (A) and Western blot (B) using monoclonal antibodies against human CRT. Mprestained protein ladders. pFDC and PFDC-CRT-10x concentrated culture media samples from $S$. cerevisiae transformed with $\mathrm{pFDC}$ vector and pFDC-CRT plasmid, respectively. Sc, Pp and $\mathrm{Hn}$ - purified CRT from S. cerevisiae, P. pastoris and human placenta, respectively. Crude lysate of $S$. cerevisiae cells transformed with $\mathrm{pFDC}$ vector was used as negative control for Western blot. Bl—blank lanes.

Additional file 4. Comparison of different CRT preparations from S. cerevisiae. Four different preparations (A, B, C, D) of purified human CRT from S. cerevisiae were analysed by SDS-PAGE (at the left) and Western blotting (at the right) using monoclonal antibodies against human CRT. M—prestained protein ladder (ThermoScientific, cat. no. 26616).

Additional file 5. Native PAGE of human placental and recombinant CRTs from the same storage buffer. Human placental CRT was transferred to the same buffer used for storage of recombinant CRTs (20 mM Tris- $\mathrm{HCl}$, $150 \mathrm{mM} \mathrm{NaCl}, 3 \mathrm{mM} \mathrm{CaCl}$, pH 7.5) and all three CRTs were analysed by electrophoresis under native conditions. Blue native PAGE is shown above and native PAGE below, all references are the same as in Fig. 2 legend.

\section{Authors' contributions}

EC conceived of the study, performed work on recombinant CRT expression and purification from yeast, high-density yeast fermentation, trypsin digestion and electrophoresis experiments, collected and analysed data, and revised manuscript. EŽ was involved in high-density yeast fermentation and trypsin digestion experiments. LIG and SCP performed CRT functional assays, JD analysed data and performed statistical analysis, and LIG revised manuscript. PH, GH purified native CRT from human placenta, were involved in native PAGE experiments, and revised the manuscript. MM and WAW were involved in functional CRT assays, MM analysed data, reviewed and revised the manuscript. RS helped to design the study, was involved in recombinant CRT expression and MS experiments, analysed, interpreted data, and drafted the manuscript. All authors read and approved the final manuscript.

\footnotetext{
Author details

1 Department of Eukaryote Gene Engineering, Institute of Biotechnology, Vilnius University, V.A. Graičiūno 8, 02241 Vilnius, Lithuania. ${ }^{2}$ Division of Translational Medicine, Department of Medicine, New York University School of Medicine, 550 First Avenue, NB17E4, New York, NY 10016, USA. ${ }^{3}$ Department of Biochemistry and Molecular Biology, University of Southern Denmark, Campusvej 55, 5230 Odense, Denmark. ${ }^{4}$ Department of Autoimmunology and Biomarkers, Statens Serum Institut, Artillerivej 5, 2300 Copenhagen, Denmark. ${ }^{5}$ Department of Biochemistry, University of Alberta, Edmonton, AB T6G 2H7, Canada.
}

\section{Acknowledgements}

The work of EC, E $\breve{Z}$ and RS was supported by the European Social Fund under the Global Grant measure grant no. VP1-3.1-ŠMM-07-K-02-038 (to R.S.). The study was also supported by grants from the Canadian Institutes of Health Research (CIHR) (to M.M.). W-A.W. is supported by a Frederick Banting and Charles Best Canada Graduate Doctoral Scholarship from CIHR. We are grateful to Audroné Rukšènaite (Vilnius University, Insitute of Biotechnology) and Dr. Algirdas Kaupinis (Vilnius University, Insitute of Biochemistry) for performing MS experiments. Kirsten Beth Hansen and Dorthe Tange Olsen are thanked for excellent technical assistance.

\section{Competing interests}

A part of the work presented in this paper was filed for international patent application WO/2014/011723.

Received: 14 July 2015 Accepted: 7 October 2015

Published online: 15 October 2015

\section{References}

1. Molinari M, Eriksson KK, Calanca V, Galli C, Cresswell P, Michalak M, Helenius A. Contrasting functions of calreticulin and calnexin in glycoprotein folding and ER quality control. Mol Cell. 2004;13:125-35.

2. Michalak M, Groenendyk J, Szabo E, Gold LI, Opas M. Calreticulin, a multiprocess calcium-buffering chaperone of the endoplasmic reticulum. Biochem J. 2009;417:651-66.

3. Tannous A, Pisoni GB, Hebert DN, Molinari M. N-linked sugar-regulated protein folding and quality control in the ER. Semin Cell Dev Biol. 2015;41:79-89.

4. Nakamura K, Zuppini A, Arnaudeau S, Lynch J, Ahsan I, Krause R, Papp S, De Smedt H, Parys JB, Muller-Esterl W, Lew DP, Krause KH, Demaurex N, Opas M, Michalak M. Functional specialization of calreticulin domains. J Cell Biol. 2001;154:961-72.

5. Bibi A, Agarwal NK, Dihazi GH, Eltoweissy M, Van Nguyen P, Mueller GA, Dihazi H. Calreticulin is crucial for calcium homeostasis mediated adaptation and survival of thick ascending limb of Henle's loop cells under osmotic stress. Int J Biochem Cell Biol. 2011;43:1187-97.

6. Gao B, Adhikari R, Howarth M, Nakamura K, Gold MC, Hill AB, Knee R, Michalak M, Elliott T. Assembly and antigen-presenting function of MHC class I molecules in cells lacking the ER chaperone calreticulin. Immunity. 2002;16:99-109.

7. Ireland BS, Brockmeier U, Howe CM, Elliott T, Williams DB. Lectin-deficient calreticulin retains full functionality as a chaperone for class I histocompatibility molecules. Mol Biol Cell. 2008;19:2413-23.

8. Gold LI, Eggleton P, Sweetwyne MT, Van Duyn LB, Greives MR, Naylor S-M, Michalak M, Murphy-Ullrich JE. Calreticulin: non-endoplasmic reticulum functions in physiology and disease. FASEB J. 2010;24:665-83.

9. Gardai SJ, McPhillips KA, Frasch SC, Janssen WJ, Starefeldt A, Murphy-UIIrich JE, Bratton DL, Oldenborg P-A, Michalak M, Henson PM. Cell-surface calreticulin initiates clearance of viable or apoptotic cells through transactivation of LRP on the phagocyte. Cell. 2005;123:321-34.

10. Chaput N, De Botton S, Obeid M, Apetoh L, Ghiringhelli F, Panaretakis T, Flament C, Zitvogel L, Kroemer G. Molecular determinants of immunogenic cell death: surface exposure of calreticulin makes the difference. J Mol Med. 2007:85:1069-76.

11. Obeid M, Tesniere A, Ghiringhelli F, Fimia GM, Apetoh L, Perfettini J-L, Castedo M, Mignot G, Panaretakis T, Casares N, Métivier D, Larochette N, van Endert P, Ciccosanti F, Piacentini M, Zitvogel L, Kroemer G. Calreticulin exposure dictates the immunogenicity of cancer cell death. Nat Med. 2007;13:54-61.

12. Wemeau M, Kepp O, Tesnière A, Panaretakis T, Flament C, De Botton S, Zitvogel L, Kroemer G, Chaput N. Calreticulin exposure on malignant blasts predicts a cellular anticancer immune response in patients with acute myeloid leukemia. Cell Death Dis. 2010;1:e104.

13. Nanney LB, Woodrell CD, Greives MR, Cardwell NL, Pollins AC, Bancroft TA, Chesser A, Michalak M, Rahman M, Siebert JW, Gold LI. Calreticulin enhances porcine wound repair by diverse biological effects. Am J Pathol. 2008;173:610-30

14. Greives MR, Samra F, Pavlides SC, Blechman KM, Naylor S-M, Woodrell CD, Cadacio C, Levine JP, Bancroft TA, Michalak M, Warren SM, Gold LI. 
Exogenous calreticulin improves diabetic wound healing. Wound Repair Regen. 2012;20:715-30.

15. Feng $M$, Chen JY, Weissman-Tsukamoto R, Volkmer J-P, Ho PY, McKenna KM, Cheshier S, Zhang M, Guo N, Gip P, Mitra SS, Weissman IL. Macrophages eat cancer cells using their own calreticulin as a guide: roles of TLR and Btk. Proc Natl Acad Sci USA. 2015;112:2145-50.

16. Tufi R, Panaretakis T, Bianchi K, Criollo A, Fazi B, Di Sano F, Tesniere A, Kepp O, Paterlini-Brechot P, Zitvogel L, Piacentini M, Szabadkai G, Kroemer G. Reduction of endoplasmic reticulum Ca2+ levels favors plasma membrane surface exposure of calreticulin. Cell Death Differ. 2008;15:274-82.

17. Panaretakis T, Kepp O, Brockmeier U, Tesniere A, Bjorklund A-C, Chapman DC, Durchschlag M, Joza N, Pierron G, van Endert P, Yuan J, Zitvogel L, Madeo F, Williams DB, Kroemer G. Mechanisms of pre-apoptotic calreticulin exposure in immunogenic cell death. EMBO J. 2009;28:578-90.

18. Peters $L R$, Raghavan $M$. Endoplasmic reticulum calcium depletion impacts chaperone secretion, innate immunity, and phagocytic uptake of cells. J Immunol. 2011;187:919-31.

19. Panaretakis T, Joza N, Modjtahedi N, Tesniere A, Vitale I, Durchschlag M, Fimia GM, Kepp O, Piacentini M, Froehlich KU, et al. The co-translocation of ERp57 and calreticulin determines the immunogenicity of cell death. Cell Death Differ. 2008;15:1499-509.

20. Ciplys E, Sasnauskas K, Slibinskas R. Overexpression of human calnexin in yeast improves measles surface glycoprotein solubility. FEMS Yeast Res. 2011;11:514-23.

21. Čiplys E, Aučynaitè A, Slibinskas R. Generation of human ER chaperone BiP in yeast Saccharomyces cerevisiae. Microb Cell Fact. 2014;13:22.

22. Čiplys E, Žitkus E, Slibinskas R. Native signal peptide of human ERp57 disulfide isomerase mediates secretion of active native recombinant ERp57 protein in yeast Saccharomyces cerevisiae. Protein Expr Purif. 2013;89:131-5.

23. Houen G, Koch C. Human placental calreticulin: purification, characterization and association with other proteins. Acta Chem Scand. 1994:48:905-11.

24. Hochstrasser DF, Frutiger S, Paquet N, Bairoch A, Ravier F, Pasquali C, Sanchez JC, Tissot JD, Bjellqvist B, Vargas R. Human liver protein map: a reference database established by microsequencing and gel comparison. Electrophoresis. 1992;13:992-1001.

25. Dupuis M, Schaerer E, Krause KH, Tschopp J. The calcium-binding protein calreticulin is a major constituent of lytic granules in cytolytic T lymphocytes. J Exp Med. 1993;177:1-7.

26. Højrup P, Roepstorff P, Houen G. Human placental calreticulin characterization of domain structure and post-translational modifications. Eur J Biochem. 2001;268:2558-65.

27. Choudhary C, Kumar C, Gnad F, Nielsen ML, Rehman M, Walther TC, Olsen JV, Mann M. Lysine acetylation targets protein complexes and coregulates major cellular functions. Science. 2009;325:834-40.

28. Pehar M, Lehnus M, Karst A, Puglielli L. Proteomic assessment shows that many endoplasmic reticulum (ER)-resident proteins are targeted by $\mathrm{N}$ (epsilon)-lysine acetylation in the lumen of the organelle and predicts broad biological impact. J Biol Chem. 2012;287:22436-40

29. Chen R, Jiang X, Sun D, Han G, Wang F, Ye M, Wang L, Zou H. Glycoproteomics analysis of human liver tissue by combination of multiple enzyme digestion and hydrazide chemistry. J Proteome Res. 2009;8:651-61.

30. Ling S, Cline EN, Haug TS, Fox DA, Holoshitz J. Citrullinated calreticulin potentiates rheumatoid arthritis shared epitope signaling. Arthritis Rheum. 2013;65:618-26.

31. Corbett EF, Michalak KM, Oikawa K, Johnson S, Campbell ID, Eggleton $P$, Kay C, Michalak M. The conformation of calreticulin is influenced by the endoplasmic reticulum luminal environment. J Biol Chem. 2000;275:27177-85.
32. Andrin C, Corbett EF, Johnson S, Dabrowska M, Campbell ID, Eggleton P, Opas M, Michalak M. Expression and purification of mammalian calreticulin in Pichia pastoris. Protein Expr Purif. 2000;20:207-15.

33. Gold LI, Rahman M, Blechman KM, Greives MR, Churgin S, Michaels J, Callaghan MJ, Cardwell NL, Pollins AC, Michalak M, Siebert JW, Levine JP, Gurtner GC, Nanney LB, Galiano RD, Cadacio CL. Overview of the role for calreticulin in the enhancement of wound healing through multiple biological effects. J Investig Dermatol Symp Proc. 2006;11:57-65.

34. Orr AW, Elzie CA, Kucik DF, Murphy-Ullrich JE. Thrombospondin signaling through the calreticulin/LDL receptor-related protein co-complex stimulates random and directed cell migration. J Cell Sci. 2003;116(Pt 14):2917-27.

35. Tolner B, Smith L, Begent RHJ, Chester KA. Production of recombinant protein in Pichia pastoris by fermentation. Nat Protoc. 2006;1:1006-21.

36. Woo JH, Liu YY, Stavrou S, Neville DM. Increasing secretion of a bivalent anti-T-cell immunotoxin by Pichia pastoris. Appl Environ Microbiol. 2004;70:3370-6.

37. Bonilla M, Nastase KK, Cunningham KW. Essential role of calcineurin in response to endoplasmic reticulum stress. EMBO J. 2002;21:2343-53.

38. Strayle J, Pozzan T, Rudolph HK. Steady-state free $\mathrm{Ca}(2+)$ in the yeast endoplasmic reticulum reaches only 10 microm and is mainly controlled by the secretory pathway pump pmr1. EMBO J. 1999;18:4733-43.

39. Kobayashi K, Kuwae S, Ohya T, Ohda T, Ohyama M, Ohi H, Tomomitsu K, Ohmura T. High-level expression of recombinant human serum albumin from the methylotrophic yeast Pichia pastoris with minimal protease production and activation. J Biosci Bioeng. 2000;89:55-61.

40. Korbelik M, Banáth J, Saw KM, Zhang W, Čiplys E. Calreticulin as cancer treatment adjuvant: combination with photodynamic therapy and photodynamic therapy-generated vaccines. Front Oncol. 2015;5:15.

41. Sambrook J, Russell DW: Molecular Cloning: A Laboratory Manual. CSHL Press; 2001.

42. Romanos M, Scorer C, Sreekrishna K, Clare J. The generation of multicopy recombinant strains. Methods Mol Biol. 1998;103:55-72.

43. Slibinskas R, Ražanskas R, Zinkevičiūtè R, Čiplys E. Comparison of first dimension IPG and NEPHGE techniques in two-dimensional gel electrophoresis experiment with cytosolic unfolded protein response in Saccharomyces cerevisiae. Proteome Sci. 2013;11:36.

44. Wiśniewski JR, Zougman A, Nagaraj N, Mann M. Universal sample preparation method for proteome analysis. Nat Methods. 2009;6:359-62.

45. Niepmann M, Zheng J. Discontinuous native protein gel electrophoresis. Electrophoresis. 2006;27:3949-51.

46. Ciplys E, Samuel D, Juozapaitis M, Sasnauskas K, Slibinskas R. Overexpression of human virus surface glycoprotein precursors induces cytosolic unfolded protein response in Saccharomyces cerevisiae. Microb Cell Fact. 2011;10:37.

47. Wessel D, Flügge UI. A method for the quantitative recovery of protein in dilute solution in the presence of detergents and lipids. Anal Biochem. $1984 ; 138: 141-3$

\section{Submit your next manuscript to BioMed Central and take full advantage of:}

- Convenient online submission

- Thorough peer review

- No space constraints or color figure charges

- Immediate publication on acceptance

- Inclusion in PubMed, CAS, Scopus and Google Scholar

- Research which is freely available for redistribution

Submit your manuscript at

www.biomedcentral.com/submit
C Biomed Central 